$11 \mid 1996$

Le développement négocié : courtiers, savoirs, technologies (I)

The genus Oryza: sources and uses of genetic variability by Susu and Limba farmers in Sierra Leone.

Malcolm S. Jusu

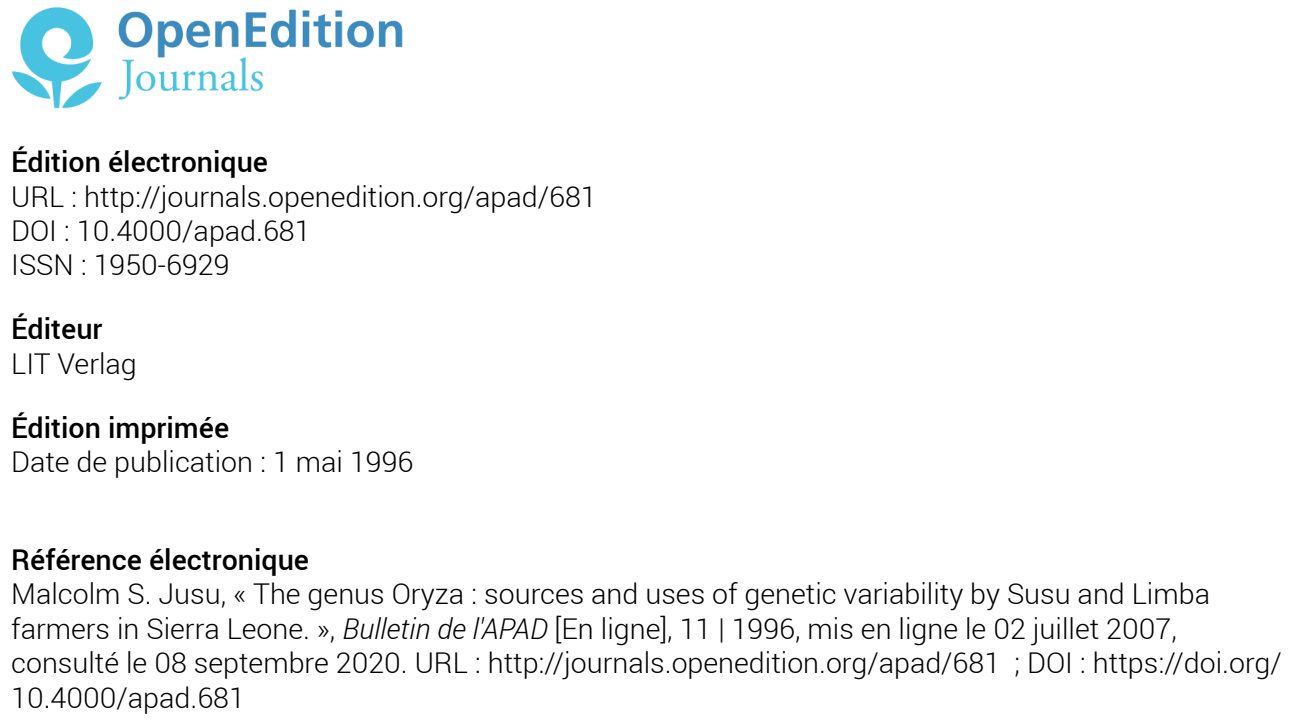

Ce document a été généré automatiquement le 8 septembre 2020

Bulletin de l'APAD 


\title{
The genus Oryza : sources and uses of genetic variability by Susu and Limba farmers in Sierra Leone.
}

\author{
Malcolm S. Jusu
}

Introduction

1 Rice has been grown by farmers in West African for centuries before the development of the present day research on the crop in the region. Plant breeders inherited from farmers a wealth of landraces that evolved through natural and human (fanner) selection. Farmer's varieties developed through evolution, selection and maintenance have resulted in a range of indigenous cultivars well adapted to the varying environmental conditions in the region. The farmers also developed local technologies which they use in their environment for the cultivation and utilization of the crop. The rice species Oryza glaberrima is indigenous to West Africa and exhibits less diversity. 118 distribution is only limited to tropical west Africa (Chang, 1975). The species was later supplemented by the introduction of the Asian cultivated species 0 . sativa probably via both trans-Sahara and coastal routes C100-500BP (Carpenter, 1978). Oryza sativa exhibits a wide diversity and is distributed and grown in all rice growing areas in the World.

In West Africa the two species of rice are cultivated as sole crops or in mixtures in farmers fields ( $\mathrm{Ng}$ et al, 1988). In addition to these two species, six of the 20 wild species of Oryza are found in Africa and two of these, o. barthii and o. longistaminata are found in fanners field as weeds with cultivated rice. The co-existence of the cultivated and wild species in association for centuries has resulted in a rich array of genetic resources selected artificially by farmers or naturally by the vagaries of nature. The resulting selections are low yielding but well-adapted to local conditions with good attributes such as resistance to diseases and pests, weed suppression ability, drought and adverse soil tolerance, and good consumer preference in terms of cooking, eating and keeping quality after cooking. 
The Rice Research Station (RRS) at Rokupr in Sierra Leone, was established in 193410 develop high yielding rice varieties and accompanying technologies suitable for the Sierra Leone fanning communities. Many rice varieties have been introduced from International and national research centers to adapt them to the five rice growing ecologies i.e uplands, in land valley swamps, bolilands, mangrove swamps, and the riverine grasslands. The most successful varieties that have been widely adapted to local conditions and adopted by fanners are local cultivars that were directly released after screening by mass selection for suitability to the upland ecology (ROK 3, Ngeima Yakei ; ROK 16, Ngovie). Also a local material Pa Willington was successfully used as one of the parents in the hybridization programme at the station for developing varieties for the lowland ecology (ROK 4, 5, 8, 9 and BD2 resulted from crosses between Pa wellington, a local cultivar, and SR26 an introduction from Southeast Asia). Some dwarf varieties such as ROK 14 were developed for high external input environments and require good water control, high rate of agro-chemical sand good cultural practices. These varieties cannot be easily adopted by poor farmers in the marginal areas in the country.

4 The RRS scientists have always considered the low income farmers in their breeding strategies. The technologies they develop cater for both high and low income farmers. There is now gaps between the on-station research results and what operates on farmers fields. To bridge this gap, more attention bas to be given to understanding the indigenous selection procedures and criteria .' of the farmer so that specific technologies can be developed in collaboration with the farmer and . field worker who directly work with them. This will involve the utilization of the indigenous knowledge of the farmer, research findings at the National Research Systems (NARS) and "International Agricultural Research Centres (IARC) for the utilization of formal scientific :methods, extension agents and NGO for the transfer of technology and the participation of donor agencies.

5 The present work will therefore entail the investigation into the sources and uses of genetic variability by two different tribes (Susu and Limba) who live in close communities in northern Sierra Leone. The result is intended to be ploughed into the research activities of RRS to help design appropriate technologies that will be adapted to their conditions and also to help increase yield stability and area of production.

Approach taken in this study includes

The study will be divided into two parts :

8 Part one : the social science studies (activity 1-4)

9 Activities 1-4 are, overall, intended to help understand fanner selection, and how and why fanner selection can be utilized in Fanner First plant improvement activities (Chambers et al. 1989). Ceccarelli et al (1995) has shown that for barley improvement, where low-resource fanners are the target group, it is advantageous to select in fanners conditions, and if possible to involve farmers directly in the selection process. The overall argument for this is that high and low performing selections in good environments often reverse places in poor environments, perhaps mainly due to unanticipated Genotype Environmental interaction. Would such a decentralized breeding programme for low-resource farmers work for rice in Sierra Leone? To answer this question we need systematic information on fanners' existing selection practices, their ideas about selection, the extent to which farmers and breeders make 
the same selection decisions in both high and low environments, and what mutual understandings (or misunderstandings) emerge, covering selection activities, when breeders and farmers interact in this way. These last two aspects (whether breeders and fanners choices are convergent when the selection environment is the same, and how any such consensus is arrived at, e.g. through reflexive monitoring of breeder and farmer activities and the negotiated "construction" of local, culturally-appropriate, plant ideotypes, are topics which have not yet been systematically investigated, either by breeders or social scientists. This, therefore, will be a major aspect of the present research programme, reflecting the additional social science training received while participating for the last six months in the Technology and Agrarian Development group at the Wageningen Agricultural University.

Part two : breeding trials (activity 5-8)

11 The genetic variability within farmers varieties collected in the study area will be evaluated. The accessions will be collected during the harvest season and grown in the field for two years to collect morphological characteristics, study the variation in flowering in landraces, study incidence of hybridization between the 0 . sativa and 0 . glaberrima varieties, agronomic practices as related to fanners activities in terms of adapting cultivars to adverse soil conditions, fertilizer application and varietal performance under competition in mixtures. The results will be used to calculate genetic distances between the species using multivariate analysis. The same material will be used in isozyme analysis using electrophoresis techniques and the results used to calculate genetic distances between the species and varieties within the species.

Activity 1 : Germplasm collection/selection

The main aim of this section is not just to assemble germplasm for subsequent genetic analysis, but to understand the local seed system. The work proposed here will complement more detailed anthropological analysis being undertaken by Kate Longley for a PhD at the University College London. What rices do farmers plant? How do they select and preserve material for planting ? Where do fanners first obtain seeds?

Two hundred farmers, both male and female, will be sampled in eight villages, belonging to two adjacent ethnic groups (four Limba and four Susu villages). Visit will be made to farmers' fields before harvest, to assess purity of stands, and numbers of off-types, and then again during harvest, in order to observe and discuss selection with the harvest teams. Specific attention will be paid to whether or not the farm owners know about panicle selection to secure pure seed, and whether or not pre-harvest panicle selection for seed purposes is carried out is any roguing done before bunching or threshing the harvest? Is seed rice set aside from the main harvest, and how is it stored ? Checks will then be instituted to find out how much selected seed is, in fact, planted back the following season. Germplasm collections will be made and passport data will include not only plant and site descriptors, but also relevant social information (e.g. socio-economic background of farmer, year the variety in question was first planted, how, where, and from whom was it acquired, why it is planted, how farmer assesses its characteristics, what local name it bears and how the farmer interprets the name). Site descriptions will include information on identity of rices being grown in adjacent plots, or in catenary sequences, and other relevant observations (e.g. cases where two varieties are deliberately mixed in the same field). Attempts will be made to reconstruct the history of introduction of some of the main varieties grown locally, by following up information about planting material farmers 
have bought, loaned, borrowed, exchanged, given away or experimented with. Initially, five farmers per village will be selected as key informant for the development of the final structured or semi-structured questionnaire that will be administered at a later stage in the field work. The key informants will be identified and selected during informal interviews, group discussions, and participatory observations during the farming operations.

It is likely that this "in depth" interviewing will be undertaken, perhaps in cooperation with Kate Longley and Paul Richards.

Rice samples will also be collected and scientific data generated according to the International Rice Research Institute (IRRI) and the West Africa Rice Development Association (WARDA) standards for Rice germplasm collection. The samples will be collected in fanners fields during harvest using one meter square quadrant per variety to study the genetic variability within farmers varieties. The samples will be analyzed in the laboratory to separate the different varieties found in each sample to determine the level of genetic variation within farmers varieties. Also seed lots preserved by farmers for next season planting will be analyzed for genetic variability.

Socio-economic data using questionnaires

The points below among others will be considered using socio-economic data collection.

General information about the farmer

- District, zone/area ; village

- Name, sex, age, religion

- Distance from main motor road, main market

- Land tenancy arrangement

19 Harvesting

- Roguing before harvesting.

- Roguing after harvesting.

- Sickle harvesting.

- Panicle harvesting.

-Way of gathering sheaves after harvest.

- Type of rope used for tying the sheaves.

20

\section{Processing methods}

b) Drying.

\section{Storage methods}

- Containers used (baskets, clothe bags, jute bags, boxes, sheaves on the head, etc.).

\section{Storage period between harvesting and processing}

- Time period in days, weeks and months.

\section{Storage condition before processing}

- Containers used for storing harvested material before storage.

a) Threshing and winnowing.

Sources of seeds for farmers.

- Relatives, friends, neighbours etc. 
- Bought, loaned, borrowed, exchanged, gift etc.

- Research institute, Seed Multiplication Project, Non Governmental Organization, Extension services etc.

- Source of knowledge about new seeds.

- Preferred seed sources.

- Purity of seeds from the various sources.

Position of the varieties on the farm

- Up slope, middle slope, bottom slope.

Ways in which the varieties are mixed during cultivation

- Erosion, broadcasting, ploughing, nursing

\section{Data analysis}

SPSS model will be used to analyze the questionnaires administered during the socio-economic data collection.

Activity $2 \mathrm{~A}$ : Stabilising selection of new varieties by farmersIntroduction

The adoption of crop varieties by fanners is governed by many factors. In the centre of origin of most cultivated crops such as in the West African Rice Zone (WARZ), fanners selection and adoption of new varieties is influenced by many factors such as agronomic, morphological, gastronomic, social and cultural characteristic of the varieties. Most of these characteristics are not normally considered by plant Breeder during the early stages of selection. In this activity some of these characters will be investigated with farmers in the study area to know which of the characters they consider most important during selection and adoption. The purpose of this activity is not only to see if farmers and breeders have convergent perceptions of what is important in selection, but how that convergence takes place. I want to monitor and follow up on what fanners think breeders are doing, as well as monitoring what we breeders are doing. This probably requires mainly follow-up interview and questionnaire work, but might also make use of so-called "focus group" discussions. Farmers will be given unfinished breeding lines under selection in the Breeding Division of RRS to see how breeders and farmers select both on farmers fields and on the RRS experimental plots. The accessions will consist of materials from early stage crosses, farmers varieties, introductions from W ARDA, and highly (physically) mixed material. The trial will be planted at the RRS and in four villages, two with the Susu and two with the Limba farmers. A group of sample fanners (ones with whom Kate had good relations ?) will be invited to participate in the trial management, selection etc.

Members of the RRS Rice Breeding Division will be invited to take part in the selection (making their own selections). Some varieties will be physically mixed to see which seed phenotypes farmers pick out and why ; because they are familiar with the variety, or the opposite ; because they don't know it, therefore want to try it. Fanner selection ability will be tested to see how good different classes of farmer are at the activity (old women, young men, Susu versus Limba etc). Whole panicles (10-15 different phenotypes) may be mixed in a bunch to see what people pick, and why. Trial test approach will also be used (group panicles in threes and ask for the odd one out, and why) as a way of assessing different informants' Personal Constructs.

Questionnaire

Socio-economic collection data using questionnaires 

collection

\section{Farmers varieties} financial constraint.

Data collection

Questionnaire
The points below among others will be considered during socio-economic data

General information about the farmer

- District, Zone/Area, Village,

- Name, Sex, Age, Religion,

- Distance from main motor road, main market,

- Land tenancy arrangement

Number of varieties grown, abandoned information about new varieties etc.

Agronomic characteristics

Duration under good and poor weather conditions, reaction to poor soil conditions, reaction to pest and diseases, weed suppression ability and birds damage

Morphological characteristics.

Grain yield in good and bad weather, Plant height, tillering capacity, sterility, Panicle length, awning, Grain length, grain width, grain husk colour and dormancy.

Gastronomic characteristics.

Base of threshing, winnowing, milling, cooking time keeping time when cooked, keeping time when husk, milled raw or parboiled, taste of cooked product, filling capacity cultural uses if any, uses for the preparation of other food products market value of product as compared to other varieties.

Other reasons for selection

Gif $t$, cultural identity, presents, exchange, market value, labour shortages and

Activity 2B : Agronomic Trials, on-farm TrialsMixing of varietiesIntroduction

This trial will simulate what Susu farmers do when they mix their varieties in the field. The advantages and disadvantages of mixing varieties will be evaluated on the station in researcher management trials and on farmers fields in farmer managed on-farm trial for yield, agronomic, morphological and gastronomic characteristics of the varieties. Four varieties will be tested.

Two O. glaberrima and two O. sativa varieties that farmers usually mix will be planted as sole varieties and in two sets in all pairwise combinations to evaluate their performance under fertilized and unfertilized regimes. The reproductive rate of the varieties (competitive ability) in mixture and as sole crops will be compared. The farmers at the end of the two years will be interviewed using questionnaires on feasibility of the trial under their conditions. On the station, a split plot design will be used (one set of the varieties will be fertilized and the other set unfertilized). All cultural practice will be according to RRS recommendations. For the on-farm trials, each community will receive two trial. One villages per community will receive the fertilized trial and the other villages will receive the unfertilized trials. The trials will be conducted for two seasons.

Data will be collected on agronomic, morphological and gastronomic characters. Data for calculating the reproductive ratio of varieties in competition will be collected. 
Socio-economic collection data using questionnaires

General information about the farmer.

- District, Zone/Area, Village,

- Name, Sex, Age, Religion,

- Distance from main motor road, main market,

- Land tenancy arrangement

- Number of farmers that carry out inter- species and inter-varietal planting.

- Reasons for inter-planting (cultural, imported idea from outside the community, learnt from within the community etc).

- comparison of farmers preferences for varieties planted in mixtures and those planted as sole crop for

Agronomic characters.

Morphological characters.

Gastronomic characters.

Activity 3 : Mass screening of local germplasm to study the overlapping of flowering between and within populations of 0 . glaberrima and 0 . sativa species. Introduction

Farmers varieties usually consist of mixed genotypes that results from admixtures, assumed natural hybrids from crosses between genotypes within populations or due to their cultural practices as it has been observed with some Susu farmers in the Kambia district in Sierra Leone who deliberately mix their varieties before seeding in the uplands. These varieties flower and come to maturity at about the same time. There is therefore a chance of hybridization between the mixed varieties or introgression within the farmers varieties. This trial will be conducted to identify varieties that have long flowering periods ( $1 \%$ to $100 \%$ ) and with similar durations (seeding to maturity). A total of fifty accessions of both $O$. Sativa and O. glaberrima varieties will be screened in the upland using a Randomized Complete Block Design ( $\mathrm{RCB}$ ) with 3 replications.

Data collection

Four plants will be fixed per plot at random for the study.

Plants adjacent to blank spaces (Gomez and De Datts, 1972), plants in the border rows, plants replanted and those affected by diseases and insects will be excluded from data collection.

The number of days from seeding to $1 \%$ (the day when the tip of the panicle emerged from the flag leaf), $50 \%$ and $100 \%$ flowering of the tillers of each selected plant and the days to maturity of each panicle will be recorded. At maturity, plant height of each panicle, number of tillers per plant, panicle length of each tiller $(\mathrm{cm})$, spikelet number per panicle, and empty spikelets per panicle will be measured.

Data analysis

60 These will include percent sterility, ANOV A of plant height, tiller number, flag leaf length and width, panicle length.

61 The duration in flowering from seeding to maturity and recording of the overlapping of flowering of the test varieties. The significance of mean value of the characters collected will be compared according to Snedecor and Cochran, 1967.

62 Note : Results obtained in this trial will help to identify possible sources of natural hybrids especially in varieties with longer flowering periods i.e. from $1 \%$ to $100 \%$ flowering 
Activity 4 : To study the incidence of hybridization in mixed stands of cultivar.

Introduction

The following three trials will be conducted to investigate what happens in farmers field when rice varieties are grown in mixtures. The incidence of hybridization in farmers fields during inter-varietal and inter-species inter-planting will be investigated. The results obtained will be used to identify characters that are related to the induction of natural hybrids in the field and to identify natural hybrids in the following generation. A representative sample of seeds will be collected from each plot and these will be grown in the second season to identify possible F1 plants that resulted from natural hybridization. Isozymes will be used as markers to confirm the hybridity of the F1 plants. All cultural practices will be according to activity 5 above.

Activity $4 \mathrm{~A}$ : Laboratory study 1

This trial will be used as a check to identify the hybrids in trials (4B) and (4C) below. Six varieties, $O$. sativa and 0 . glaberrima varieties will be crossed artificially in the laboratory area to generate FI seeds. Varieties mostly mixed by farmers intentionally and RRS varieties will be tested. A RCB design with 3 replications will be used. The number of combinations $=15(\mathrm{Vl}+\mathrm{V} 2, \mathrm{Vl}+\mathrm{V} 3, \mathrm{Vl}+\mathrm{V} 4, \mathrm{Vl}+\mathrm{V} 5, \mathrm{Vl}+\mathrm{V} 6, \mathrm{~V} 2+\mathrm{V} 3, \mathrm{~V} 2+\mathrm{V} 4, \mathrm{~V} 2+\mathrm{V} 5$, $\mathrm{V} 2+\mathrm{V} 6, \mathrm{~V} 3+\mathrm{V} 4, \mathrm{~V} 3+\mathrm{V} 5, \mathrm{~V} 3+\mathrm{V} 6, \mathrm{~V} 4+\mathrm{V} 5, \mathrm{~V} 4+\mathrm{V} 6, \mathrm{~V} 5+\mathrm{V} 6)$. The varieties will be artificially crossed (emasculated) in reciprocal crosses. The trial will be conducted at the laboratory area in plastic buckets. Two seedlings per variety per bucket will be planted. The induction of flowering, fertilization and cultural practices will be similar to $4 \mathrm{~B}$ and $4 \mathrm{C}$ below.

The F1 seeds will be germinated in petri dishes to compare the morphological characteristics of the seedlings from the parents and those from the hybrids. Where differences are difficult to see. The seeds will be planted in the fields and the F1 plants grown to maturity to study the plants during the vegetative and reproductive phases, and the panicle and seed characteristics of the varieties. These characters will be used as markers to identify the natural hybrids in $4 \mathrm{~B}$ and $4 \mathrm{C}$ below.

Activity 4B : Laboratory study 2

This will be similar to trial $4 \mathrm{~A}$ and will be conducted in plastic bucket in the field laboratory area. Flowering will be induced to synchronize the flowering of all the test varieties. Six weeks after transplanting the plants will be induced to flower by placing them in the dark room for 16 hour i.e. from 17 hours in the evening to 9 hours the following morning. This will be done for 16 day. The plants will be exposed to normal light and will start to flower in the next 15 to 18 days. The plants will be covered with transparent polyethylene bags to concentrate the pollen in the buckets until the end of flowering. The F1 seeds will be grown and characters identified in $4 \mathrm{~A}$ above as markers will be used to access the percentage of artificial hybridization.

Activity $4 \mathrm{C}$ : Field study

Six varieties as in $4 \mathrm{~A}$ and $4 \mathrm{~B}$ above will be evaluated in the upland ecology for the production of natural hybrids. Varieties mostly mixed by farmers intentionally and RRS varieties will be tested. A RCB design with 3 replications will be used. The varieties will be harvested at maturity and the seeds grown in the second season for the identification of artificial hybrids as in $4 \mathrm{~A}$ and $4 \mathrm{~B}$ above.

$\mathrm{A}$ as a backup to activities $4 \mathrm{~A}$ and $4 \mathrm{~B}$ for accidental failure of varieties, the same varieties will also be planted as part of the hybridization block in the field where the plants will be planted in four stages at two weeks intervals to synchronize flowering. 
Data analysis

ing area and data analysis will be similar to activity 3 above. The results will be compared with those obtained in activity above to identify characters that are related to the production of high rate of natural hybrids. The incidence of hybridization will be estimated as a percentage of hybrids found in the offspring population in the following season.

Activity 5 : Morphological description of landracesIntroduction

The important questions to address here are :

- what are the main differences between farmers varieties?

- how is the genetic diversity distributed over the varieties?

71 generated using 50 accessions of 0 . sativa and 0 . glaberrima varieties. Farmer's varieties collected during germplasm collection will be grown for two consecutive years in randomized Complete Block Design (RCB) with 3 replications. The other practices in terms of number of seedlings per bill, spacing between plots, fertilizer rates and application, and cultural practices will be according to RRS protocol. The IRRI standard evaluation system for rice will be used for data collection for vegetative and reproductive characters. The data will be used to perform univariate analysis within varieties, multivariate analysis to measure the genetic distances between the varieties in each species and between the two species. The result will be compared with results obtained by other authors in other areas (Second, 1982, 1985a, b, Glazmann,1985, Miezan et al, 1985 ).

Data analysisHeritability

Heritability of the characters will be calculated using the genotype and season interaction from the ANOVA table. The ANOVA table will also be used to estimate means and standard deviations of the characters. Univariate analysis will be used to calculate the variation within the varieties (use 20 plants in each variety for data collection).

Multivariate statistical analysis

The Principal Component Analysis (PCA), Canonical Variate Analysis (CVA) and Cluster analysis will be used 10 compare the relative amount of variation between the varieties and the species. If the species and the varieties within the species are not related, the population of the accession will not be fully separated by multivariate analysis. (CPA and CVA, Chatfield and Collin, 1980)

Activity 6. Biochemical description of landracesIntroduction

74 The measurement of morphological variation in plants (rice) is usually influenced by environmental factors. The characters measure the adaptation of the population to habitat (ecological adaptation) instead of being an objective measure of genetic variation. The genetic bases of morphological characters is often polygenic and this makes it difficult for direct translation of phenotypes into genotypes, although there is a clear relation. Electrophoresis is often used to access the genetic variation of population for distinct allelic forms of isozymes.

75 The main advantage is that isozymes are not like characters that are influenced by environmental factors since they are codominant and hence identification of heterozygotes is possible. 

system that we have found to be applicable in detecting variations in the land races of O. sativa and O. glaberrima and to determine whether the found allelic variations can be used to determine genetic variations in the following materials. be tested to compare the isozyme variation between the hybrids and the parents (progenitors) to confirm hybridity of the crosses.

2. All the fifty accessions tested in activity 5 will be tested for further variations using isozyme markers.

3. Variations in the RRS released varieties maintained by the breeding Division of RRS and those that have been grown by farmers for at lest five years to find out if any genetic changes have occurred in the se varieties due to natural or artificial selection by farmers or due to intentional or unintentional mixing by farmers.

4. The variation within farmers varieties with the same names will be tested.

The analysis will be according to BIOSYS-l (Slender and Snowford, 1981 and 1983), Neis gene diversity statistic (Nei, 1973, 1978) and CPA and CV A (Chatfield and Collin, 1980).

Results from PCA and Cluster analysis based on isozyme patterns will be compared with those on morphological data.

\section{BIBLIOGRAPHIE}

Balandier, G (1948) Economy of the Kakossa, Kabak and Matakong Islands (Lower Guinea).Translated by Wardrop, T. N, In Farm and Forest (January to June, 1948).

Carpenter, A. J. (1978). The history of rice in Africa. Pages 3 to 10. In Academic Press. Rice in Mrica . London.

Chambers, R. ; Pacey, A. and Thrupp, L.A. (1989). Farmer First : Farmers innovation and agricultural research. Intermediate Technology Publications, $1989.218 \mathrm{pp}$

Carpenter, A. J. (1978). The history of rice in Africa. pp 3 - 10. In academic Press. Rice in Africa. London.

Ceccarelli, S. ; Grando, S. and R.H. Booth (1995). Farmers participatory research in selection Paper presented at the participatory Breeding Workshop held at the International Agricultural Center (IAC), Wageningen 26 - 28th July, 1995.

Chatfield, C. and Collin, A.J. (1980). Introduction to multivariate analysis, London, Chapman and Hall.

Chang, T.T. (1975). Exploration and survey in rice. In Frankell, O.H. and J.G. Hawkes (ed). crop genetic resources for today and tomorrow, Cambridge. pp 159 - 165.

Chang, T.T. (1976). The rice culture. In the early history of agriculture. Royal Society of London.

Gottleb, L.D. (1982). Conservation and duplication of isozymes in plants. Science $216: 373380$. 
Glazmann, J.C. (1985). Varietal classification of Asian Rice (O. sativa) based on isozyme polymorphism. In Rice Genetics (IRRI) Proceedings of the International Rice Genetic Symposium, 27 30th May, 1985.

Hardon, J.J. and W.S. de Boef (1993). Linking farmers and breeders in local crop development. In cultivating knowledge, genetic diversity, farmer experimentation and crop research. Walter de Boef, Kojo Amanor and Kate Wellard (ed.). London. IT Publications.

Longley (1995). Local seed management and crop improvement among the Susu of West Africa. Preliminary report on Ph. research, Dept. of Anthropology, University College London.

Miezan K. and A. Chesquiere (1985). Genetic structure of African traditional Rice cultivars. In Rice Genetics (IRRI) Proceedings of the International Rice Genetic Symposium, 27 - 30th May, 1985.

Nei (1973). The theory and estimation of genetic distances. pp 45 - 54. In genetic structure of populations. N. E. Morton (ed). University of Hawaii press, Honolulu.

Nei (1978). Estimation of average heterozygosity and genetic distance from a small number of individuals. Genetics 89 : 583 - 590 .

Ng, N. Q. (1982). Rice species in Africa and their germplasm collection, preservation, evaluation and documentation programme at IITA. Paper presented to the participants of the upland rice monitoring tour sponsored by IDESSA/IRRI/IRAT and co-sponsored by W ARDA/IIT A/CIAT on the 28th, September 1982.

Ng, N. Q. ; Chang, T.T. ; Vaughan ; Zuno, C. ; and P. Altoveros (1982). African rice diversity, conservation and prospects for improvement. In proceedings of an international conference of crop genetic resources of Africa, held at IITA, Ibadan Nigeria from the 17th - 20th October, 1988.

Richards, P. (1991). Mende names for rice. Cultural analysis of an agricultural knowledge system. In H. Tillman (ed). Proceedings of workshop on agricultural knowledge system and the role of extension. Institut für Agrasoziologie, Universität Hohenheim, Stuttgart.

Richards P. (1995). Culture and community values in the selection and maintenance of African rices. In S. Bush (ed). Intellectual property and indigenous knowledge. Inland Press, Covelo. CA.

Richard, P. (1995). Farmer knowledge and plant genetic resource management Paper prepared for DES/ ATSAF/IPGRI workshop on in situ conservation and sustainable plant genetic resources for food and agriculture in developing countries. May 2nd to 4th, 1995. Bonn, Roettgen BRD.

Second, G. (1982). Origin of genetic diversity of cultivated rice (Oryza spp). Study of the polymorphism scored at 40 loci. Jap. Jour. Of Genetics $57: 25$ - 57.

Second, G. (1985 a). Evolutionary relationship in the sativa group of Oryza based on isozyme data. gen. sel. Evol.17: 89 - 114 .

Second, G. (1985 a). Geographical origin, genetic diversity and the molecular dock hypothesis in Oryza. In p. Jaquard, G. Hein and J. Antonovics (ed). Genetic differentiation and dispersal in plants. pp 42 - 56. Springer Verlag, Berlin.

\section{AUTEUR}

MALCOLM S. JUSU

Rokupr Rice Research Station ; Ministry of Agricultural, Freetown (Siena Leone) 